Pacific Journal of Mathematics

ON CONTINUITY OF FUNCTIONS WITH VALUES IN VARIOUS 


\section{ON CONTINUITY OF FUNCTIONS WITH VALUES IN VARIOUS BANACH SPACES}

\section{WALTER A. STRAuss}

In the discussion of weak solutions of certain kinds of partial differential equations, a crucial point, which is isolated in this paper, concerns the proof of identities of energy type and of the continuity of the solutions, which two questions are intimately related. The continuity referred to is with respect to a distinguished independent real variable $t$, the other variables being suppressed into some Banach space.

In $\S 2$ a simple argument shows that an essentially bounded function of $t$ with values in a space $V$ is automatically weakly continuous in $V$ provided it is weakly continuous in some larger space.

In $\$ 3$ conditions are found under which a square-integrable function $u(t)$ with values in $V$ is strongly continuous in $V$ (Theorem 3.3). Roughly speaking, the main condition is that there exist self-adjoint linear operators $A(t)$ coercive with respect to $V$ such that $A(\cdot) u(\cdot)$ and $d u / d t$ lie in spaces which are dual to each other.

The proof is based on an energy identity (Theorem 3.1). Theorem 3.3 has application to certain equations of the form

$$
A(t) u(t)=(\text { possibly }) \text { nonlinear terms in } d u / d t
$$

(cf. [5]).

The analogous strong continuity and energy problems for equations like (cf. [4])

$$
d^{2} u / d t^{2}+A(t) u(t)=\text { (possibly) nonlinear terms }
$$

are considered in $\S 4$. These results are used in [6].

Torelli [7] solved these problems in the case of linear equations (1.2). Partial results for the nonlinear case of (1.2) were obtained in [4] and [1] and for (1.1) in [5]. Here Torelli's method is generalized so as to be applicable in the nonlinear case of (1.2) as well as to (1.1). In each of these cases variants of a regularization procedure of Lions and Prodi [3] for the Navier-Stokes equations are used. Lions [2] also proves a different case of Theorem 3.2 .

2. Weak continuity. We begin with some definitions. If $V$ is a Banach space and $\Omega$ is a real closed interval then by $L^{p}(\Omega ; V)$ we mean the space of all strongly measurable functions $u$ on $\Omega$ into $V$ such that 


$$
\|u\|^{p}=\int_{\Omega}|u(t)|_{V}^{p} d t<\infty
$$

if $1 \leqq p<\infty$ and

$$
\|u\|=\operatorname{ess} \sup \left\{|u(t)|_{V}, t \in \Omega\right\}
$$

if $p=\infty$. By $C_{w}(\Omega ; V)$ (resp. $C_{s}(\Omega ; V)$ ) we mean the subspace of $L^{\infty}(\Omega ; V)$ consisting of those functions which are a.e. equal to weakly (resp. strongly) continuous functions with values in $V$. Primes on a function of $t$ denote (weak) derivatives with respect to $t$. For a space $V, V^{\prime}$ denotes the "dual" space of all continuous conjugate-linear functions on $V$.

THeorem 2.1. Let $V$ and $Y$ be Banach spaces, $V$ reflexive, $V a$ dense subset of $Y$ and the inclusion map of $V$ into $Y$ continuous. Then

$$
L^{\infty}(0, T ; V) \cap C_{w}(0, T ; Y)=C_{w}(0, T ; V) .
$$

Proof. Let $u$ be weakly continuous with values in $Y$ and $u \in L^{\infty}(0, T ; V)$. We must show that it is also weakly continuous with values in $V$. (The converse is obvious.) It suffices to prove that there is a constant $M$ such that

$$
u(t) \in V \text { and }|u(t)|_{V} \leqq M \text { for all } t \in[0, T] .
$$

Indeed, if (2.1) is true we can choose from any convergent net $t_{n} \rightarrow t_{0}$ of numbers $[0, T]$ a subnet $t_{m}$ such that $u\left(t_{m}\right)$ converges weakly in $V$. Since $u$ is weakly continuous with values in $Y$, the limit of this subnet must be $u\left(t_{0}\right)$. Therefore $u\left(t_{n}\right) \rightarrow u\left(t_{0}\right)$ weakly in $V$.

To prove (2.1) we define approximate delta-functions $\eta_{\varepsilon}(t)$ in the usual way: let $\eta_{0}(t)$ be a nonnegative even $C^{\infty}$-function on the real line with compact support and integral one; define $\eta_{\varepsilon}(t)=\varepsilon^{-1} \eta_{0}(t / \varepsilon)$ for $\varepsilon>0$. Now consider $0<t<T$ so that $\left(\eta_{\varepsilon} * u\right)(t) \in V$ for sufficiently small $\varepsilon$. Let $M$ be the norm of $u$ in $L^{\infty}(0, T ; V)$. Then

$$
\left|\left(\eta_{\varepsilon} * u\right)(t)\right|_{V} \leqq \int \eta_{\varepsilon}(s)|u(t-s)|_{V} d s \leqq M .
$$

So there exists a net of $\varepsilon$ 's such that $\left(\eta_{\varepsilon} * u\right)(t)$ converges weakly in $V$. On the other hand, for all $v \in Y^{\prime}$,

$$
\left(\left(\eta_{\varepsilon} * u\right)(t)-u(t), v\right) \rightarrow 0 \quad \text { as } \quad \varepsilon \rightarrow 0
$$

since $(u(s), v)$ is a continuous function of $s$. It follows that $u(t) \in V$,

$$
\left(\eta_{\varepsilon} * u\right)(t) \rightarrow u(t) \quad \text { weakly in } V
$$


and $|u(t)|_{V} \leqq M$.

To prove (2.1) for the case $t=0$, we apply a similar argument with $\left(\eta_{\varepsilon} * u\right)(t)$ replaced by $\left(\eta_{\varepsilon} * u\right)(\varepsilon)$; and for $t=T$, we consider $\left(\eta_{\varepsilon} * u\right)(T-\varepsilon)$.

COROLlary 2.1. Let $V$ and $W$ be Banach spaces, $V$ reflexive, both contained in some fixed linear space, and $V \cap W$ dense in $V$ and in $W$. If $u \in L^{\infty}(0, T ; V)$ and $u^{\prime}=d u / d t \in L^{1}(0, T ; W)$, then there exists a weakly continuous function on $[0, T]$ with values in $V$ which is equal to $u$ almost everywhere.

Proof. The space $Y=V+W$ satisfies the conditions of Theorem 1. The assumptions on $u$ imply, in particular, that $u \in L^{1}(0, T ; Y)$ and $u^{\prime} \in L^{1}(0, T ; Y)$. Therefore $u$ is weakly continuous with values in $Y$, and Theorem 2.1 may be applied.

3. Strong continuity. We are given a reflexive Banach space $V$ and a family of hermitian linear operators $A(t): V \rightarrow V^{\prime}(0 \leqq t \leqq T)$ which are weakly continuously differentiable functions of $t$. If $u \in L^{1}(0, T ; V)$, we denote by $A u$ the function $t \rightarrow A(t) u(t)$ and by $A^{\prime} u$ the function $t \rightarrow[d A(t) / d t] u(t)$. By the uniform boundedness principle, $A(t)$ and $A^{\prime}(t)=d A(t) / d t$ are uniformly bounded operators from $V$ to $V^{\prime}$. The pairing between elements of $V$ and $V^{\prime}$ is denoted by $($,$) .$

Secondly, we are given another Banach space $W$ as well as a linear space containing both $V$ and $W$ such that $V \cap W$ is dense in $V$ and $W .{ }^{1}$ In addition, $Z$ is a Banach space such that

$$
Z \subset L^{1}(0, T ; W), \quad Z^{\prime} \subset L^{1}\left(0, T ; W^{\prime}\right)
$$

as dense subsets with continuous inclusion. If $f \in Z^{\prime}, u \in Z$ and $\langle f, u\rangle$ indicates the pairing, we assume that $(f(t), u(t))$ [pairing in $W$ ] is integrable and

$$
\langle f, u\rangle=\int_{0}^{T}(f(t), u(t)) d t .
$$

Furthermore, we assume that multiplications by step functions map $Z$ into $Z$ and that translations in $t$ are continuous in the strong operator topology on $Z$ (where functions are extended to be zero outside $[0, T]$ when necessary).

Theorem 3.1. Let $u \in L^{\infty}(0, T ; V),{ }^{2} u^{\prime}=d u / d t \in Z$ and $A u \in Z^{\prime}$. Then for every $t \in[0, T]$

1 Elements of $V^{\prime}$ and $W^{\prime}$ are identified if they agree on $V \cap W$.

2 Whence $A u \in L^{\infty}\left(0, T ; V^{\prime}\right)$ and $u^{\prime}$ is a distribution with values in $V$. 


$$
(A(t) u(t), u(t))-(A(0) u(0), u(0))=\int_{0}^{t}\left(A^{\prime} u, u\right)+2 \operatorname{Re} \int_{0}^{t}\left(A u, u^{\prime}\right) .
$$

Proof. By Corollary 2.1 we may assume that $u$ is weakly continuous with values in $V .{ }^{3}$ We shall prove (3.2) for a fixed $t=t_{0}$, $0<t_{0} \leqq T$. Let $\theta_{0}$ be the characteristic function of the interval $\left[0, t_{0}\right]$; for small $\delta>0$, let $\theta(t)=\theta_{\delta}(t)$ be 1 for $t \in\left[\delta, t_{0}-\delta\right]$, zero for $t \notin\left(0, t_{0}\right)$ and linear in the intervals $[0, \delta]$ and $\left[t_{0}-\delta, t_{0}\right]$. Next $\eta(t)=$ $\eta_{\mathrm{s}}(t)$ is defined as in the proof of Theorem 1 as an approximate deltafunction.

For any $C^{\infty}$-function $v$ with values in $V$ with compact support, we have

$$
0=\int_{-\infty}^{\infty} d(A v, v)=\left\langle A^{\prime} v, v\right\rangle+2 \operatorname{Re}\left\langle A v, v^{\prime}\right\rangle .
$$

Putting $v=\eta *(\theta u)$ and noting that

$$
v^{\prime}=\eta^{\prime} * \theta u=\eta *\left(\theta^{\prime} u\right)+\eta *\left(\theta u^{\prime}\right),
$$

we have

$$
\left\{\begin{aligned}
0= & \left\langle A^{\prime}(\eta * \theta u), \eta * \theta u\right\rangle \\
& +2 \operatorname{Re}\left\langle\eta * \theta A u, \eta * \theta u^{\prime}\right\rangle+2 \operatorname{Re}\left\langle\eta * \theta A u, \eta * \theta^{\prime} u\right\rangle \\
& +2 \operatorname{Re}\left\langle A(\eta * \theta u)-\eta * \theta A u, \eta^{\prime} * \theta u\right\rangle .
\end{aligned}\right.
$$

We shall examine each term in (3.3) separately as $\theta=\theta_{\delta} \rightarrow \theta_{0}$ and $\eta$ is fixed. (The idea of first letting $\delta \rightarrow 0$ is due to Torelli [7].)

Since $\eta^{(j)} \in L^{\infty}(R)$ and $\theta \rightarrow \theta_{0}$ in $L^{1}(R)$ as $\delta \rightarrow 0$, we have $\eta^{(j)} * \theta u \rightarrow$ $\eta^{(j)} * \theta_{0} u$ in $L^{\infty}(R, V)$ strongly $(j=0,1)$. Therefore, as $\delta \rightarrow 0, \theta$ may be replaced by $\theta_{0}$ in the first and last terms in (3.3). The same is true of the second term in view of Lebesgue's convergence theorem because $u \in L^{1}(0, T ; W)$ and $A u \in L^{1}\left(0, T ; W^{\prime}\right)$.

As for the third term in (3.3), we note that $\eta * \eta *\left[\left(\theta-\theta_{0}\right) A u\right] \rightarrow 0$ in $L^{\infty}\left(R, V^{\prime}\right)$ strongly while

$$
\int\left|\theta^{\prime}(t)\right| d t=2
$$

Thus $\left\langle\eta *\left(\theta-\theta_{0}\right) A u, \eta * \theta^{\prime} u\right\rangle \rightarrow 0$ as $\delta \rightarrow 0$. On the other hand, since $\left(\left(\eta * \eta * \theta_{0} A u\right)(t), u(t)\right)$ is a continuous function of $t,\left\langle\eta * \eta * \theta_{0} A u, \theta^{\prime} u\right\rangle$ tends to

$$
\left(\left(\eta * \eta * \theta_{0} A u\right)(0), u(0)\right)-\left(\left(\eta * \eta * \theta_{0} A u\left(t_{0}\right), u\left(t_{0}\right)\right) .\right.
$$

Hence the third term in (3.3) also tends to the latter expression. Writing $F=A u$, we conclude that

\footnotetext{
${ }^{3}$ Thus in (3.2), we are referring to the weakly continuous function.
} 


$$
\left\{\begin{aligned}
0= & \left\langle A^{\prime}\left(\eta * \theta_{0} u\right), \eta * \theta_{0} u\right\rangle+2 \operatorname{Re}\left\{\left\langle\eta * \theta_{0} F, \eta * \theta_{0} u^{\prime}\right\rangle\right. \\
& +\left(\left(\eta * \eta * \theta_{0} A u\right)(0), u(0)\right)-\left(\left(\eta * \eta * \theta_{0} A u\right)\left(t_{0}\right), u\left(t_{0}\right)\right) \\
& \left.+\left\langle A\left(\eta * \theta_{0} u\right)-\eta * \theta_{0} A u, \eta^{\prime} * \theta_{0} u\right\rangle\right\} .
\end{aligned}\right.
$$

We now consider the convergence of each term in (3.4) separately as $\varepsilon \rightarrow 0\left(\eta=\eta_{\varepsilon}\right)$. Since $\eta * \theta_{0} u \rightarrow \theta_{0} u$ strongly in $L^{2}(R, V)$, the first term tends to $\left\langle A^{\prime} \theta_{0} u, \theta_{0} u\right\rangle$. By a standard argument using the assumption that translations in $t$ are continuous in $Z, \eta * \eta * \theta_{0} u^{\prime} \rightarrow \theta_{0} u^{\prime}$ strongly in $Z$. Thus the second term tends to $2 \operatorname{Re}\left\langle\theta_{0} F, \theta_{0} u^{\prime}\right\rangle$. Now if we let $\rho=\rho_{\varepsilon}=\eta_{\varepsilon} * \eta_{\varepsilon}$, then $0 \leqq \rho(t)=O\left(\varepsilon^{-1}\right)$, the support of $\rho$ is an interval of length $O(\varepsilon)$, and

$$
\int_{0}^{\infty} \rho(t) d t=\frac{1}{2} \int_{-\infty}^{\infty} \rho(t) d t=\frac{1}{2} .
$$

Therefore for sufficiently small $\varepsilon$,

$$
\begin{aligned}
& \left(\left(\rho * \theta_{0} A u\right)\left(t_{0}\right)-\frac{1}{2}(A u)\left(t_{0}\right), u\left(t_{0}\right)\right) \\
& \quad=\int_{0}^{t_{0}} \rho(t)\left((A u)\left(t_{0}-t\right)-(A u)\left(t_{0}\right), u\left(t_{0}\right)\right) d t .
\end{aligned}
$$

Since the inner product within this integral is a continuous function of $t$, we conclude that as $\varepsilon \rightarrow 0$,

$$
\left(\left(\rho_{\varepsilon} * \theta_{0} A u\right)\left(t_{0}\right), u\left(t_{0}\right)\right) \rightarrow \frac{1}{2}\left(A\left(t_{0}\right) u\left(t_{0}\right), u\left(t_{0}\right)\right) .
$$

In a similar way we find the same result with $t_{0}$ replaced by 0 .

The proof is terminated once we show that the last term in (3.4) tends to zero with $\varepsilon$. Since

$$
\int\left|\eta_{\varepsilon}^{\prime}(t)\right| d t=O\left(\varepsilon^{-1}\right)
$$

$\left\{\varepsilon \eta_{\varepsilon}^{\prime} * v\right\}$ is bounded in $L^{2}(R, V)$, where we have put $v=\theta_{0} u$. But for fixed $\varepsilon_{1}, \varepsilon \eta_{\varepsilon}^{\prime} *\left(\eta_{\varepsilon_{1}} * v\right)=\varepsilon\left(\eta_{\varepsilon} * \eta_{\varepsilon_{1}}^{\prime} * v\right)$ tends to zero strongly in $L^{2}(R, V)$ as $\varepsilon \rightarrow 0$. It follows that

$$
\varepsilon \eta_{\varepsilon}^{\prime} * v \rightarrow 0 \quad \text { strongly in } L^{2}(R, V) .
$$

On the other hand,

$$
\left[A\left(\eta_{\varepsilon} * v\right)-\eta_{\varepsilon} *(A v)\right](t)=\int[A(t)-A(t-s)] \eta_{\varepsilon}(s) v(t-s) d s .
$$

Therefore

$$
\left\|A\left(\eta_{\varepsilon} * v\right)-\eta_{\varepsilon} *(A v)\right\|_{L^{2}\left(V^{\prime}\right)}=O\left(\varepsilon\left\|\eta_{\varepsilon} * v\right\|_{L^{2}(V)}\right)=O(\varepsilon) .
$$

Thus the last term in (3.4) tends to zero with $\varepsilon$. 
Corollary 3.1. $(A(t) u(t), u(t))$ is a continuous function of $t$.

THEOREM 3.2. Assume in addition that $(c>0, \lambda$ real $)$ :

$$
(A(t) v, v)+\lambda|v|_{X}^{2} \geqq c|v|_{V}^{2}
$$

for all $v \in V$, where $X$ is some Banach space containing both $V$ and $W$ with continuous inclusions. Then the function $u$ in Theorem 3.1 is strongly continuous with values in $V$.

Proof. Suppose $t_{n} \rightarrow t$ in $[0, T]$. Then $\left|u\left(t_{n}\right)-u(t)\right|_{X} \rightarrow 0$ since both $u$ and $u^{\prime}$ lie in $L^{1}(0, T ; X)$. By Corollary 3.1,

$$
\left(A(t) u\left(t_{n}\right), u\left(t_{n}\right)\right) \rightarrow(A(t) u(t), u(t)) .
$$

Therefore, by the weak continuity

$$
\left(A(t)\left(u\left(t_{n}\right)-u(t)\right), u\left(t_{n}\right)-u(t)\right) \rightarrow 0 .
$$

By (3.5), $\left|u\left(t_{n}\right)-u(t)\right|_{V} \rightarrow 0$.

THEOREM 3.3. In Theorem 3.2 the assumption $u \in L^{\infty}(0, T ; V)$ can be weakened to $u \in L^{2}(0, T ; V)$.

Proof. We begin with identity (3.3), but fix $\theta=\theta_{\delta}$ and let $\varepsilon \rightarrow 0$ first. By arguments similar to those following $(3.4)$, (cf. $[4,5])$, we find

$$
0=\left\langle\theta A^{\prime} u, \theta u\right\rangle+2 \operatorname{Re}\left\langle\theta F, \theta u^{\prime}\right\rangle+2 \operatorname{Re}\left\langle\theta A u, \theta^{\prime} u\right\rangle .
$$

Next, as $\delta \rightarrow 0$, the first two terms in (3.6) approach the right hand side of (3.2) with $t=t_{0}$. However, the third term may not converge since the function $t \rightarrow(A(t) u(t), u(t))$ is not known to be continuous. We alter the definition of $\theta$ as follows: $\theta(t)=\theta_{\delta}(t)$ is 1 in $\left[t_{1}+\delta, t_{0}-\delta\right]$, zero outside of $\left(t_{1}, t_{0}\right)$ and otherwise linear, where $0<t_{1}<t_{0}<T$. Then letting $\delta \rightarrow 0$ in (3.4) gives for almost every $t_{1}$ and $t_{0}$.

$$
\begin{array}{r}
\left(A\left(t_{0}\right) u\left(t_{0}\right), u\left(t_{0}\right)\right)-\left(A\left(t_{1}\right) u\left(t_{1}\right), u\left(t_{1}\right)\right) \\
=\int_{t_{1}}^{t_{0}}\left\{\left(A^{\prime} u, u\right)+2 \operatorname{Re}\left(A u, u^{\prime}\right)\right\} .
\end{array}
$$

In particular, the function $t \rightarrow(A(t) u(t), u(t))$ is essentially bounded. From (3.5) it follows that $u \in L^{\infty}(0, T ; V)$ and so the situation is reduced to that of Theorem 3.2.

4. Solutions of hyperbolic equations. The assumptions are the same as in $\S 3$ except that we are also given a Hilbert space $H$ containing $V$, where $V$ is dense in $H$ and the inclusion is continuous; 
$H$ and $W$ are contained in some fixed linear space. The analogue to Theorem 3.1 is:

THEOREM 4.1. Let $u \in L^{\infty}(0, T ; V), u^{\prime} \in Z \cap L^{\infty}(0, T ; H)$ and

$$
u^{\prime \prime}+A u=F \in Z^{\prime}+L^{1}(0, T ; H)
$$

where $u^{\prime}=d u / d t, u^{\prime \prime}=d^{2} u / d t^{2}$. Then for every $t \in[0, T]$

$$
\begin{gathered}
\left|u^{\prime}(t)\right|_{B}^{2}+(A(t) u(t), u(t))-\left|u^{\prime}(0)\right|_{H}^{2}-(A(0) u(0), u(0)) \\
\quad=\int_{0}^{t}\left(A^{\prime} u, u\right)+2 \operatorname{Re} \int_{0}^{t}\left(F, u^{\prime}\right) .
\end{gathered}
$$

Proof. By Corollary 2.1, $u \in C_{w}(0, T ; V)$. By (4.1),

$$
u^{\prime \prime} \in Z^{\prime}+C_{w}\left(0, T ; V^{\prime}\right) \subset L^{1}\left(0, T ; W^{\prime}+V^{\prime}\right) \text {. }
$$

Thus Corollary 2.1 may be applied again to infer that $u^{\prime} \in C_{w}(0, T ; H)$. Using the notation $\theta=\theta_{\delta}$ and $\eta=\eta_{\varepsilon}$ as before, we have

$$
\begin{aligned}
0= & 2 \operatorname{Re}\left\langle\eta * \theta u^{\prime}, \eta^{\prime} * \theta u^{\prime}\right\rangle \\
= & 2 \operatorname{Re}\left\{\left\langle\eta * \theta u^{\prime}, \eta * \theta u^{\prime \prime}\right\rangle\right. \\
& \left.+\left\langle\eta *\left(\theta-\theta_{0}\right) u^{\prime}, \eta * \theta^{\prime} u^{\prime}\right\rangle+\left\langle\eta * \theta_{0} u^{\prime}, \eta * \theta^{\prime} u^{\prime}\right\rangle\right\} .
\end{aligned}
$$

Since $\eta \in L^{\infty}(R), \theta \rightarrow \theta_{0}$ in $L^{1}(R)$ and $\theta^{\prime}$ is bounded in $L^{1}(R)$ as $\delta \rightarrow 0$ in addition to the fact that $u^{\prime} \in C_{w}(0, T ; H)$, the last term in (4.3) tends to

$$
2 \operatorname{Re}\left\{\left(\left(\eta * \eta * \theta_{0} u^{\prime}\right)(0), u^{\prime}(0)\right)-\left(\left(\eta * \eta * \theta_{0} u^{\prime}\right)\left(t_{0}\right), u^{\prime}\left(t_{0}\right)\right)\right\}
$$

and the next-to-last term tends to zero as $\delta \rightarrow 0$. Thus, if we add (4.3) to (3.3) and let $\delta \rightarrow 0$, we find that (3.4) holds except for the addition of expression (4.4) to its right-hand side, where $F=u^{\prime \prime}+A u$ now.

Next we let $\varepsilon \rightarrow 0$. Since

$$
\begin{aligned}
& \left(\left(\rho_{\varepsilon} * \theta_{0} u^{\prime}\right)\left(t_{0}\right)-\frac{1}{2} u^{\prime}\left(t_{0}\right), u^{\prime}\left(t_{0}\right)\right) \\
& \quad=\int_{0}^{t_{0}} \rho_{\varepsilon}(t)\left(u^{\prime}\left(t_{0}-t\right)-u^{\prime}\left(t_{0}\right), u^{\prime}\left(t_{0}\right)\right) d t
\end{aligned}
$$

tends to zero with $\varepsilon$, the terms (4.4) approach

$$
\left|u^{\prime}(0)\right|_{H}^{2}-\left|u^{\prime}\left(t_{0}\right)\right|_{H}^{2},
$$

Thus, referring to the proof of Theorem 3.1, we find (4.2) (with $t=t_{0}$ ).

CoRollary 4.1. $\left|u^{\prime}(t)\right|_{H}^{2}+(A(t) u(t), u(t))$ is a continuous function of $t$. 
THEOREM 4.2. Assume in addition that (3.5) holds for all $v \in V$, with $X=H$. Then $u \in C_{s}(0, T ; V)$ and $u^{\prime} \in C_{s}(0, T ; H)$.

Proof. If $t_{n} \rightarrow t$ in $[0, T]$ then

$$
\left|u^{\prime}\left(t_{n}\right)\right|_{H}^{2}+\left(A(t) u\left(t_{n}\right), u\left(t_{n}\right)\right) \rightarrow\left|u^{\prime}(t)\right|_{H}^{2}+(A(t) u(t), u(t)) .
$$

Hence by the weak continuity,

$$
\left|u^{\prime}\left(t_{n}\right)-u^{\prime}(t)\right|_{H}^{2}+\left(A(t)\left(u\left(t_{n}\right)-u(t)\right), u\left(t_{n}\right)-u(t)\right) \rightarrow 0 .
$$

But since $u \in C_{s}(0, T ; H)$ and in view of (3.5),

$$
\varlimsup
$$

Hence $\left|u^{\prime}\left(t_{n}\right)-u^{\prime}(t)\right|_{H} \rightarrow 0$ and $\left|u\left(t_{n}\right)-u(t)\right|_{V} \rightarrow 0$.

Theorem 4.3. In Theorem 4.2 the assumptions $u \in L^{\infty}(0, T ; V)$ and $u^{\prime} \in L^{\infty}(0, T ; H)$ may be weakened to $u \in L^{2}(0, T ; V)$ and $u^{\prime} \in$ $L^{2}(0, T ; H)$, if $F \in Z^{\prime}+L^{2}(0, T ; H)$.

Proof. (cf. Theorem 3.3.) Letting $\varepsilon \rightarrow 0$ first, we have (3.6) but with the additional term

$$
2 \operatorname{Re}\left\langle\theta u^{\prime}, \theta^{\prime} u^{\prime}\right\rangle \text {. }
$$

Then letting $\delta \rightarrow 0$ we conclude that the function

$$
t \rightarrow\left|u^{\prime}(t)\right|_{H}^{2}+(A(t) u(t), u(t))
$$

is essentially bounded. Since $u \in C_{s}(0, T ; H)$, it follows that $u^{\prime} \in L^{\infty}$ $(0, T ; H)$ and $u \in L^{\infty}(0, T ; V)$.

REMARK. A slight variation of the proof shows that under the same conditions,

$$
\begin{aligned}
& \varphi(t)\left[\left|u^{\prime}(t)\right|_{H}^{2}+\right.(A(t) u(t), u(t)] \\
&-\varphi(0)\left[\left|u^{\prime}(0)\right|_{H}^{2}+(A(0) u(0), u(0))\right] \\
&=\int_{0}^{t}\left[\varphi\left(A^{\prime} u, u\right)+\varphi^{\prime}(A u, u)+\varphi^{\prime}\left|u^{\prime}\right|_{H}^{2}+2 \varphi \operatorname{Re}\left(F, u^{\prime}\right)\right],
\end{aligned}
$$

for $0 \leqq t \leqq T$ and any $C^{1}$-function $\varphi$ on $[0, T]$ 


\section{BIBLIOGRAPHY}

1. G. Andreassi and G. Torelli, Su una equazione di tipo iperbolico non lineare, Rend. Sem. Mat. Padova 35 (1965), 134-147.

2. J. L. Lions, Quelques remarques sur les ćquations différentielles opérationnelles du $1^{\text {er }}$ ordre, Rend. Sem. Mat. Padova 33 (1963).

3. J. L. Lions and G. Prodi, Un théorème d'existence et unicité dans les équations de Navier-Stokes en dimension 2, C. R. Acad. Sci., Paris, 248 (1959), 3519-21.

4. J. L. Lions and W. A. Strauss, Some non-linear evolution equations, Bull. Soc. Math. Fr. (1965).

5. W. A. Strauss, Evolution equations non-linear in the time-derivative, J. Math. Mech. (1966).

6. W. A. Strauss, The initial-value problem for certain non-linear evolution equations (to appear)

7. G. Torelli, Un camplemento ad un theorema di J. L. Lions sulle equazioni differenziali astratte del secondo ordine, Rend. Sem. Mat. Padova 34 (1964), 224-241.

Received September 24, 1965.

STANFORd University 



\section{PACIFIC JOURNAL OF MATHEMATICS}

\section{EDITORS}

H. SAMELSON

Stanford University

Stanford, California

J. P. JANS

University of Washington

Seattle, Washington 98105

\section{J. DuGUNDJI}

University of Southern California

Los Angeles, California 90007

RICHARD ARENS

University of California

Los Angeles, California 90024

\section{ASSOCIATE EDITORS}

E. F. BECKENBACH
B. H. NEUMANN

F. WOLF

K. YoSIDA

\section{SUPPORTING INSTITUTIONS}

\author{
UNIVERSITY OF BRITISH COLUMBIA \\ CALIFORNIA INSTITUTE OF TECHNOLOGY \\ UNIVERSITY OF CALIFORNIA \\ MONTANA STATE UNIVERSITY \\ UNIVERSITY OF NEVADA \\ NEW MEXICO STATE UNIVERSITY \\ OREGON STATE UNIVERSITY \\ UNIVERSITY OF OREGON \\ OSAKA UNIVERSITY \\ UNIVERSITY OF SOUTHERN CALIFORNIA
}

\author{
STANFORD UNIVERSITY \\ UNIVERSITY OF TOKYO \\ UNIVERSITY OF UTAH \\ WASHINGTON STATE UNIVERSITY \\ UNIVERSITY OF WASHINGTON \\ AMERICAN MATHEMATICAL SOCIETY \\ CHEVRON RESEARCH CORPORATION \\ TRW SYSTEMS \\ NAVAL ORDNANCE TEST STATION
}

Mathematical papers intended for publication in the Pacific Journal of Mathematics should be typewritten (double spaced). The first paragraph or two must be capable of being used separately as a synopsis of the entire paper. It should not contain references to the bibliography. Manuscripts may be sent to any one of the four editors. All other communications to the editors should be addressed to the managing editor, Richard Arens at the University of California, Los Angeles, California 90024 .

50 reprints per author of each article are furnished free of charge; additional copies may be obtained at cost in multiples of 50 .

The Pacific Journal of Mathematics is published monthly. Effective with Volume 16 the price per volume (3 numbers) is $\$ 8.00$; single issues, $\$ 3.00$. Special price for current issues to individual faculty members of supporting institutions and to individual members of the American Mathematical Society: $\$ 4.00$ per volume; single issues $\$ 1.50$. Back numbers are available.

Subscriptions, orders for back numbers, and changes of address should be sent to Pacific Journal of Mathematics, 103 Highland Boulevard, Berkeley 8, California.

Printed at Kokusai Bunken Insatsusha (International Academic Printing Co., Ltd.), No. 6, 2-chome, Fujimi-cho, Chiyoda-ku, Tokyo, Japan.

\section{PUBLISHED BY PACIFIC JOURNAL OF MATHEMATICS, A NON-PROFIT CORPORATION}

The Supporting Institutions listed above contribute to the cost of publication of this Journal, but they are not owners or publishers and have no responsibility for its content or policies. 


\section{Pacific Journal of Mathematics

Vol. 19, No. $3 \quad$ July, 1966

S. J. Bernau, The spectral theorem for unbounded normal operators .......

Lu-san Chen, Asymptotic behavior of solutions of parabolic equations of

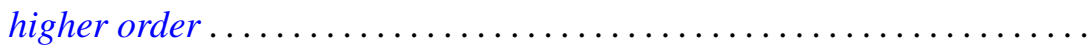

Lawrence William Conlon, An application of the Bott suspension map to the

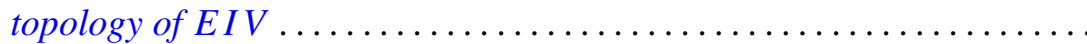

Neal Eugene Foland and John M. Marr, Sets with zero-dimensional kernels .........................................

Stanley Phillip Franklin and R. H. Sorgenfrey, Closed and image-closed

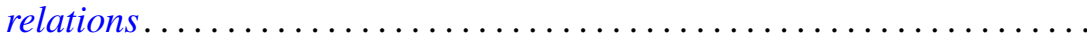

William Jesse Gray, A note on topological transformation groups with a

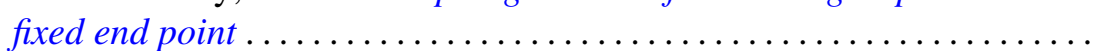

Myron Goldstein, $K$ - and L-kernels on an arbitrary Riemann surface ...... 449

George Joseph Kertz and Francis Regan, The exponential analogue of a generalized Weierstrass series .............................

Walter Leighton, On Liapunov functions with a single critical point ........ 467

Bernard Werner Levinger and Richard Steven Varga, On a problem of $O$.

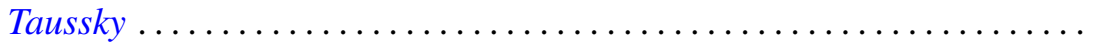

Lowell Duane Loveland, Tame subsets of spheres in $E^{3} \ldots \ldots \ldots \ldots \ldots . .489$

Erik Andrew Schreiner, Modular pairs in orthomodular lattices ......... 519

K. N. Srivastava, On dual series relations involving Laguerre polynomials ...............................

Arthur Steger, Diagonability of idempotent matrices.....

Walter Strauss, On continuity of functions with values in various Banach spaces...

Robert Vermes, On the zeros of a linear combination of polynomials ...

Elliot Carl Weinberg, On the scarcity of lattice-ordered matrix rings ....

Harold Widom, Toeplitz operators on $H_{p} \ldots \ldots \ldots \ldots \ldots$

Neal Zierler, On the lattice of closed subspaces of Hilbert space...

Irving Leonard Glicksberg, Correction to: "Maximal algebras and a theorem of Rado"

John Spurgeon Bradley, Correction to: "Adjoint quasi-differential operators of Euler type"

William Branham Jones, Erratum: "Duality and types of completeness in locally covex spaces".

Stanley P. Gudder, Erratum: "Uniqueness and existence properties of bounded observables" 